\title{
Graphical criticism: some historical notes
}

\author{
Hadley Wickham
}

November 19, 2012

\section{Introduction}

Gelman and Unwin have written a thought-provoking paper that compares and contrast the goals and outputs of "statistical data graphics" and "infographics". The paper is unfortunately weakened by confusion between infographics and infovis, and between design and decoration. This is a shame as there's nothing more likely to enrage any group of humans than mislabelling them. This makes it less likely that the paper will engender much change, even though their recommendations are sound.

In brief: Infographics and infovis are not the same. Infovis is a speciality of computer science with its own academic traditions and conferences. A number of statisticians, including myself, are already active in this community (e.g. Wilkinson et al. (2005); Wickham et al. $(2010))$. It's easy to get involved and have an impact: like most computer science conferences, all submissions are reviewed and program committee members are always desperate to find good reviewers. Infographics, on the other hand, are a genre of art (or design); they are artworks that use a data set as a creative constraint, rather like haikus and limericks. The dataset as a whole receives minimal attention, with most time spent on creative and attractive arrangement of graphical elements generated from individual data points. As Gelman and Unwin point out, this may be great for getting people to look at the plot in the first place, but it's not so helpful for generating understanding or insight.

The authors also seem a little confused between design and decoration: designers do more than put lipstick on a pig. In the words of Vitaly Friedman, editor-in-chief of Smashing magazine, "good design is about effective communication, not decoration at the expense of legibility." Good design is an important part of any visualisation, while decoration (or chart-junk) is best omitted. Statisticians should also be careful about comparing themselves to artists and designers; our goals are so different that we will fare poorly in comparison. Is the average journal article as entertaining as 20 (or 60) pages from a Dan Brown novel? Probably not; but why should it be?

For the rest of the paper, I'll ignore these confusions and focus on placing Gelman and Unwin's comments in a historical perspective. I'm probably not qualified to do so (being younger than both of the authors), but it's interesting to see how long statisticians have been pointing out problems with other people's visualisations, and how little impact it has had. 


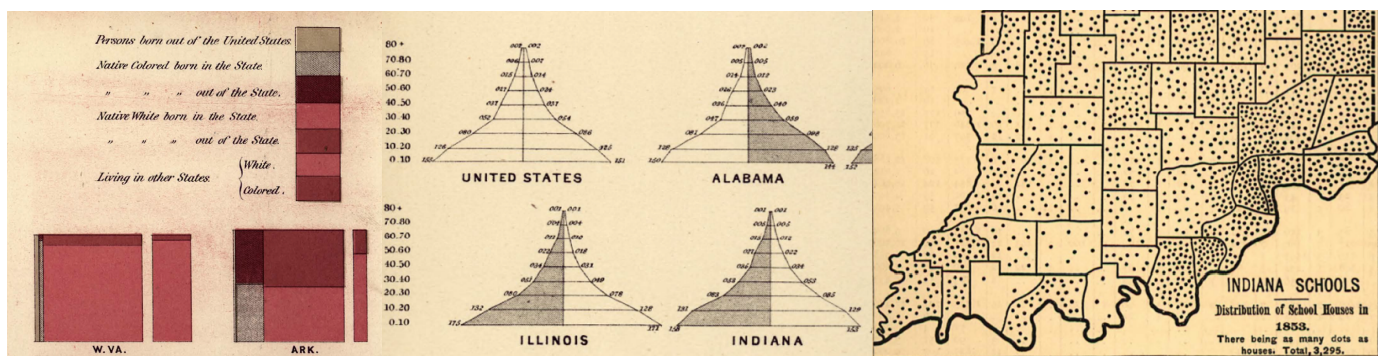

Figure 1: From left to right: a mosiac plots (plate 20), population pyramids (plate 39) and a dot-density map (page 59) from ?.

\section{Some history}

An early American highlight of great graphics was the "Statistical Atlas of the United States", produced in 1870, 1880, and 1890 for the 8th, 9th and 10th censuses. As well as beautifully illustrated maps (choropleth and dot-density), they show early examples of mosaic plots, population pyramids and parallel coordinates plots. Figure 1 shows a few examples. I thoroughly recommend spending some time pouring over the high-quality scans made available by the Library of Congress at http://memory.loc.gov/ammem/gmdhtml/census.html, or if you don't want to read the whole thing, http://www.handsomeatlas.com/ highlights some particularly interesting selections.

I mention the statistical atlas to show that it is not technology that limits our ability to make useful and engaging graphics. Excellent graphics were possible (with a lot of work), well before the advent of computers.

However, we do have evidence that not all graphics of the time were equally good. It was only a few years later, in 1901, when some of the first formal instructions for good visualisation were introduced at the International Institute of Statistics. Some of the recommendations included:

1. "We must keep symbols to a minimum, so as not to overload the reader's memory. Some ancient authors, by covering their cartograms with hieroglyphics, made them indecipherable."

2. "One of us recommends adopting scales for ordinate and abscissa so the average slope of the phenomenon corresponds to the tangent of the curve at an angle of $45^{\circ}$.

3. "Areas are often used in graphic representations. However, they have the disadvantage of often misleading the reader even though they were designed according to indisputable geometric principles. Indeed, the eye has a hard time appreciating areas."

4. "We should not, as it is sometimes done, cut the bottom of the diagram under the pretext that it is useless. This arbitrary suppression distorts the chart by making us think that the variations of the function are more important than they really are." 
5. "In order to increase the means of expression without straining the reader's memory, we often build cartograms with two colors. And, indeed, the reader can easily remember this simple formula: "The more the shade is red, the more the phenomenon studied surpasses average; the more the shade is blue, the more phenomenon studied is below average.'"

These recommendations seem amazingly prescient. Two and three were not verified experimentally until almost 90 years later (Cleveland et al., 1988; Cleveland and McGill, 1987); one and four are recommendations that many people still forget; and in five, it's interesting to note that the colour recommendation is for blue and red: is this an early recognition of consequences of red-green colour blindness? Unfortunately, according to Funkhouser (1937), the "report was torn to pieces and there seemed to be no inclination to formulate any resolutions in regard to it."

Tracking down these recommendations is a testament to the power of the internet for research. My first source was Funkhouser (1937), an excellent review of statistical graphics written in 1930's, which I had read from a PDF downloaded from JSTOR. This provided translation of some of the recommendations, and a reference to the original guidelines: "Propositions relatives l'uniformit apporter dans le l'tablissement des graphiques" published in the "Bulletin de l'Institut International de Statistique" ("Proposals to bring uniformity to the preparation of charts" in the "Bulletin of the International Statistical Institute", translated by google translate). Some googling lead me to http://gallica.bnf.fr/ark: /12148/cb327209133, the website for the National Library of France, which has scanned versions of all issues of the bulletin. That got me to the French original, but I needed an English translation. To find out the best way, I asked for advice on twitter, and based on the response, I used http://oDesk.com to find a French-English translator who translated the 6-page document in 2 hours for around $\$ 30$. All-in-all, it took less than a day to locate and translate a 110 year-old document! (A full copy of the recommendations is included in the supplemental material)

Another milestone was Munsell (1907). Munsell developed one of the first perceptually sound theories of colour, based on the three components of hue (the "name" of the colour), value (the "lightness" of the colour) and chroma (the "strength" of the colour), as illustrated in Figure 2 (in later work, he adjusted the shape of the colour sphere to better approximate human perception). Munsell developed harmonious ways of picking colours (by using moderate chroma and varying only one component at a time), advice which took quite some time to make its way into the statistical graphics literature Ihaka (2003); Zeileis et al. (2009). Far too many visualisations use jarring, over-saturated colours, or use colour gradients that introduce perceptual artefacts (like the infamous rainbow colour scale).

Like bright colours, 3d graphics are eye-catching and engaging, and were developed surprisingly early in the history of statistical graphics. Figure 3 shows a 3 d graphic published in 1880 using data from the Swedish census (Perozzo, 1880). It only took a few years for critiques to appear: "As for diagrams in three dimensions, at which we have seen many attempts, notably those of M. Berg in Stockholm and of M. Perozzo in Rome, they are ingenious tours de force, which we amateurs and experts, ought to admire and cover with 


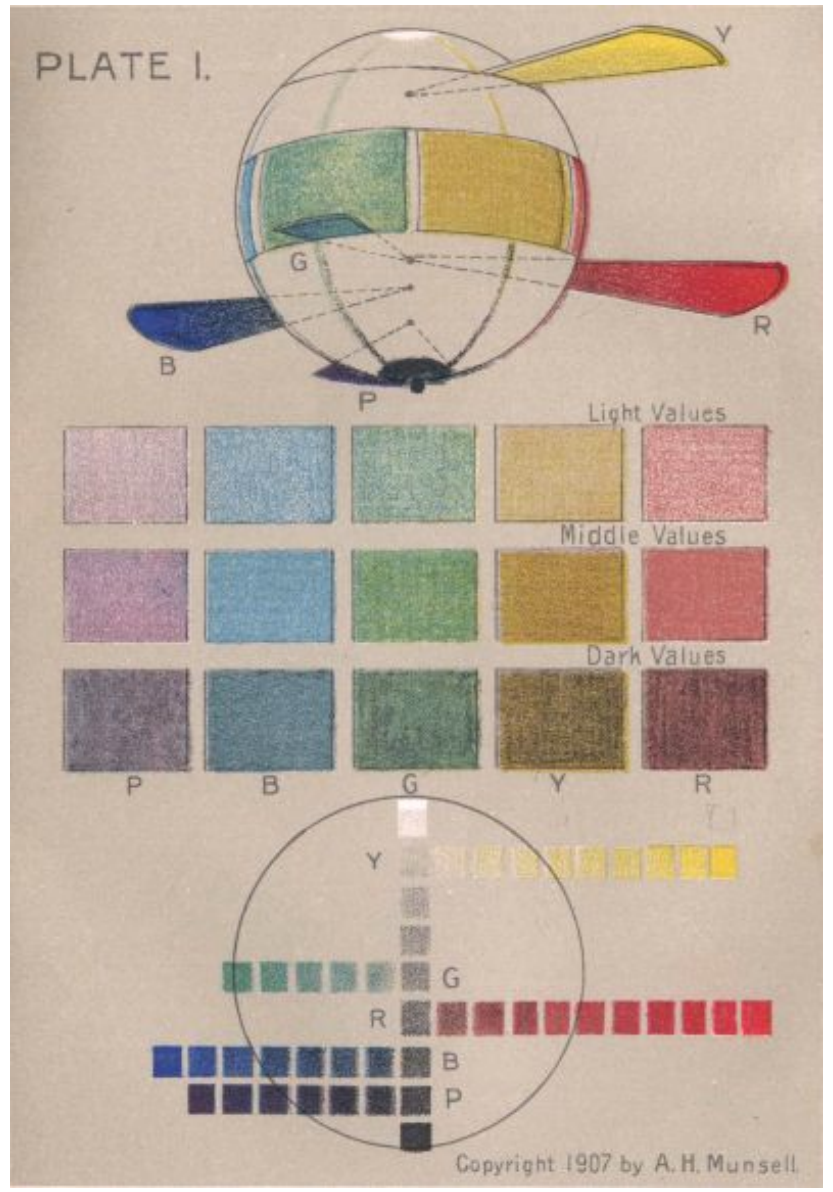

Figure 2: Munsell's colour system as described in Munsell (1907) 
eulogies but not imitate if we are practical people." (Block, 1886, p. 417).

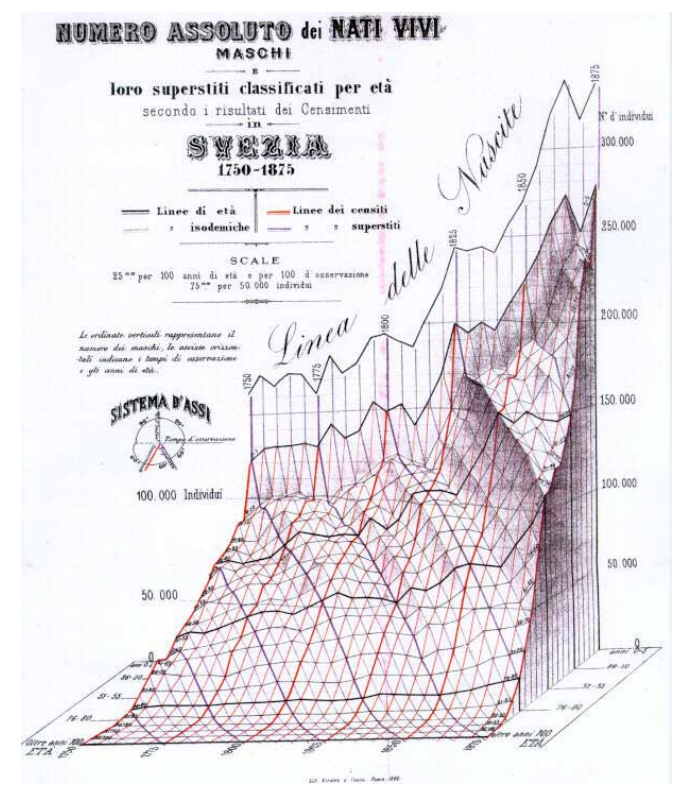

Figure 3: A stereogram showing the absolute number of survivors of male birth classified by age and year (Perozzo, 1880).

80 years later, Kenneth Haemer made similar points in The American Statistician, pointing out the "perils of perspective" (Haemer, 1947b), and showing why 3d bar charts are such a bad idea (Haemer, 1951). This amazes me: even when drawing a 3d bar chart required significantly more effort than a 2d barchart (not just clicking a button in Excel), people were still using them to visualise their data. What is it that draws us to $3 d$ visualisations?

(I thoroughly recommend reading the full set of The American Statistician articles by Haemer: Haemer (1949c, 1948c, 1949a, 1948b, 1947a, 1948a, 1950b, 1949b, 1950a) - they are readily available from JSTOR)

There were also infographics of this era, as Spear (Spear, 1952) critiqued: "If, on the other hand, the message is more clearly expressed as a statement, a graph should not be used. Too often presentations are made that add confusion to the meaning, and a chart is made just for the sake of making a chart". She also contributed Figure 4, any early satire of the informationless graphic. A modern equivalent is Phil Gyford's "infographic", http: //www.flickr.com/photos/philgyford/4505748943/; a small sample of which is shown in Figure 5 .

\section{Conclusions}

There is little evidence that the quality of the best graphics has improved over the last hundred years. I wonder if technology serves primarily as a quantity-multiplier, rather than a quality-multiplier. It's somewhat easier to reproduce the best graphics of the last 100 years today; it's much easier to reproduce the mediocre graphics of the last 100 years. If that is 


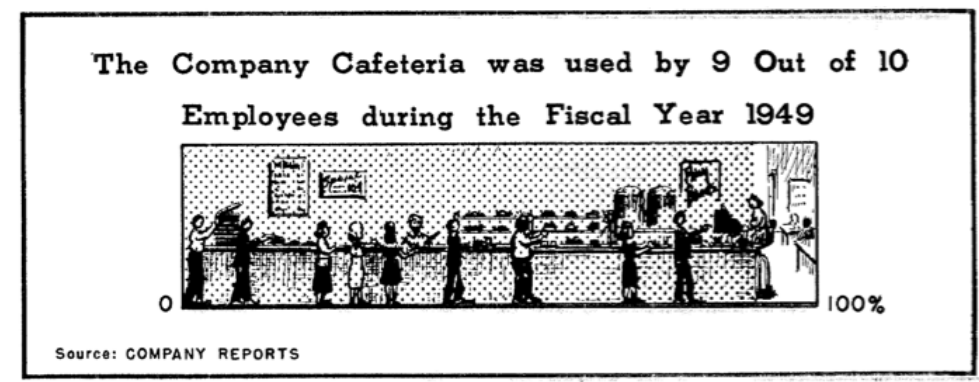

Fig. 1-2. An unnecessary chart.

Figure 4: An early ironic infographic

so, how can we help people make better visualisations, visualisations that both illuminate the unknown and unexpected, while also helping to engage interest and effect change? Why do people create graphics, like $3 \mathrm{~d}$ barcharts, that are more work than simpler equivalents that would display more information? Why do people favour flash over content? Until we know the answer to these questions, it seems likely that the advice of Unwin, Gelman and many others will continue to be ignored by the majority of graph makers.

\section{References}

M. Block. Traité théorique et pratique de statistique. Paris, 2nd edition, 1886.

W. S. Cleveland and R. McGill. Graphical perception: The visual decoding of quantitative information on graphical displays of data. Journal of the Royal Statistical Society. Series A (General), 150(3):192-229, 1987.

W. S. Cleveland, M. E. McGill, and R. McGill. The shape parameter of a two-variable graph. Journal of the American Statistical Association, 83(402):289-300, 1988.

H. G. Funkhouser. Historical development of the graphical representation of statistical data. Osiris, 3:269-404, 1937. URL http://www. jstor.org/stable/301591.

K. Haemer. Question 23: Graphic presentation. The American Statistician, 3(5):10-10, 1949a.

K. W. Haemer. Hold that line. The American Statistician, 1(1):25-25, 1947a.

K. W. Haemer. The perils of perspective. The American Statistician, 1(3):19-19, 1947b.

K. W. Haemer. Double scales are dangerous. The American Statistician, 2(3):24-24, 1948a.

K. W. Haemer. Question 9: Negative numbers and semilog paper. The American Statistician, $2(2): 18-18,1948 b$.

K. W. Haemer. Range-bar charts. The American Statistician, 2(2):23-23, 1948c. 


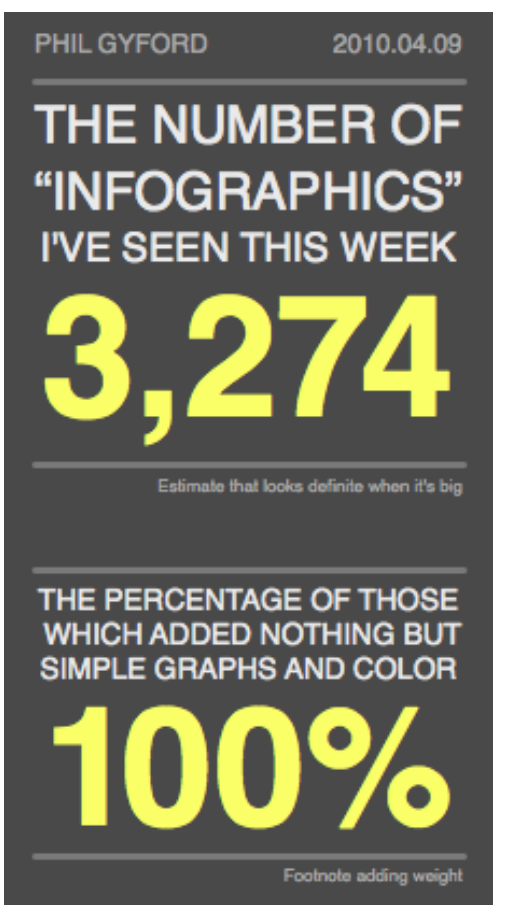

Figure 5: A recent satire of infographics

K. W. Haemer. Area bias in map presentation. The American Statistician, 3(2):19-19, 1949b.

K. W. Haemer. The supplementary-scale chart. two charts for the price of one. The American Statistician, 3(3):11-11, 1949c.

K. W. Haemer. A simplified ranking chart. The American Statistician, 4(5):21-21, 1950a.

K. W. Haemer. Color in chart presentation. The American Statistician, 4(2):20-20, $1950 \mathrm{~b}$.

K. W. Haemer. The pseudo third dimension. The American Statistician, 5(4):28-28, 1951.

R. Ihaka. Colour for presentation graphics. In Proceedings of the 3rd International Workshop on Distributed Statistical Computing (DSC 2003), 2003. URL http://www.ci.tuwien. ac.at/Conferences/DSC-2003/Proceedings/Ihaka.pdf.

A. H. Munsell. A color notation. Geo. H. Ellis Co., Boston, 1907. URL http://www. gutenberg.org/2/6/0/5/26054/.

L. Perozzo. Della rappresentazione graphica di una collettività di individui nella successione del tempo. Annali di Statistica, 12(1-16), 1880.

M. E. Spear. Charting Statistics. McGraw-Hill Book Company, Inc., 1952. 
H. Wickham, D. Cook, H. Hofmann, and A. Buja. Graphical inference for infovis. IEEE Transactions on Visualization and Computer Graphics (Proc. InfoVis '10), 16(6):973-979, Nov.-Dec. 2010. [26\% acceptance rate. Best paper award.].

L. Wilkinson, A. Anand, and R. Grossman. Graph-theoretic scagnostics. In IEEE Symposium on Information Visualization, pages 157-164, 2005.

A. Zeileis, K. Hornik, and P. Murrell. Escaping RGBland: Selecting colors for statistical graphics. Computational Statistics \& Data Analysis, 53:3259-3270, 2009. URL http: //statmath.wu-wien.ac.at/ zeileis/papers/Zeileis+Hornik+Murrell-2008.pdf. 